\title{
Creating Agents of Change through Doctoral Learning
}

\author{
Aubrey L. C. Statti \\ The Chicago School of Professional Psychology \\ astatti@thechicagoschool.edu \\ Kelly M. Torres \\ The Chicago School of Professional Psychology \\ ktorres@thechicagoschool.edu
}

\begin{abstract}
This article seeks to provide a case study of a doctoral program aspiring to create change through student progress and provide an overview of how they have structured program curricula to promote academic and professional growth and empower students to become global leaders. Further, this article is focused on providing a focus on the importance of learning technologies and how doctoral students develop the skill sets and expertise needed to employ technology into educational and organizational contexts to enhance academic outcomes, instructional approaches, and employee productivity. Particularly, information is provided on the importance of providing students access to cutting edge technologies that are transforming the landscape of educational and organizational learning.
\end{abstract}

\section{KEYWORDS}

learning technologies, professional growth, organizational learning, student empowerment

In the present culture of higher education, education doctoral programs have a responsibility to prepare future leaders and agents of change through advanced scholarly learning. Further, affiliate institutions of the Carnegie Project on the Education Doctorate (CPED) "focus on developing scholarly practitioners, [--] individuals who have the knowledge, skills, and dispositions they need to solve the problems of practice they routinely encounter" (Zambo et al., 2015, p. 233). This article seeks to introduce a case study of a doctoral program aspiring to create action and change through student progress. This piece also strives to provide an overview of how the program's structured curricula promotes academic and professional growth as well as empowers students to become global leaders and advocates. Further, this article is focused on providing a focus on the importance of learning technologies and how doctoral students develop the skill sets and expertise needed to employ technology into educational and organizational contexts to enhance academic outcomes, instructional approaches, and employee productivity. Recommendations are made regarding the importance of providing students access to cutting edge technologies that are transforming the landscape of educational and organizational learning.

Kremers et al. (2019) explained that vital importance of bridging the gap between knowledge and change. In this regard, they identified five critical aspects of developing change agents: transdisciplinary collaboration and community; intellect and innovation; emotional intelligence and well-being; energy and commitment; and reflexivity, reflection, and action. Further, they advocated for the evaluation of graduate learning spaces and posited for the need for creativity and diversity in program approaches, stating "instead of encouraging conformity,

New articles in this journal are licensed under a Creative Commons Attribution 4.0 United States License. experimentation and providing space for the exchange of information to learn from one another should be encouraged" (para 2). Additionally, Ciok (2019) defined what it means to be an agent of change as "someone who listens to the people in the community where the issue exists and makes sure that they truly understand the root of the problem before implementing a new idea", encouraging learners to "find your passion and act on it" (para 3). While the terminology is relatively modern and the research still in progress, the value of creating agents of change is present and growing in doctoral programs.

The article begins with a brief overview of the program being evaluated and also reviews the curriculum rigor and standards of the program. Further, the article provides specific examples of how the EdD program under investigation is utilizing innovative technologies in order to create agents of change who are inspired to action in their global and local communities. Additionally, a discussion of how the curriculum is focusing on issues of social justice through innovative technology-enhanced curriculum design is presented. Further, initiatives of interprofessional education, program residencies, and how mentorship relationships are beneficial to creating student agents of change capable of action and advocacy are analyzed. As an example of these active learning strategies, instances of training and engagement with communities through service learning projects and study abroad opportunities are discussed. Finally, the commentary concludes with a discussion of the future of the doctoral program.
This journal is supported by the Carnegie Project on the Education Doctorate: A Knowledge Forum on the EdD (CPED) cpedinitiative.org 


\section{BACKGROUND ON EDD IN EPT PROGRAM}

The Chicago School of Professional Psychology (TCSPP) and its educational degree programs, including the Doctorate of Education (EdD) in Educational Psychology and Technology (EPT), are regionally accredited by The Western Association of Schools and Colleges Senior College and University Commission (WSCUC). The professional doctorate, also referred to as the EdD in this article, focuses on developing experienced professionals through professional practice and the extension of student professional knowledge base (Lundgren-Resenterra \& Kahn, 2019). The threeyear EPT program prepares students to develop the knowledge and skills needed to work in the evolving field of learning technologies. Students develop the expertise needed to critically evaluate instructional approaches, assess educational challenges, and critique technology-driven methods that may impact student learning, curriculum design, and employee performance. Upon completion of the EPT program, graduates are empowered to be agents of change in which they are able to effectively assess and understand how individuals and organizations learn, perform, utilize technology, and promote program productivity and sustainability.

The EPT program requirements include:

- 51 hours of core program coursework and 6 hours of concentration coursework.

- two on-campus residencies (professional development and networking sessions).

- a competency examination (which includes a professional practice project).

- a dissertation (which may include either a traditional dissertation or action research dissertation approach).

Program core coursework is focused on various aspects of learning, teaching, culture, lifespan development, professional development, ethics, and the impact of technology on these areas. Further, core coursework includes an emphasis on quantitative and qualitative methodologies and action research. Students in the EPT program also complete concentration coursework focused on K-12 education learning and technology, higher education learning and technology, or instructional design.

\section{CURRICULUM RIGOR}

The EPT program faculty and TCSPP leaders are dedicated to providing students high quality and rigorous learning experiences that are tied to industry standards and encompass best practices for online learning. All courses include signature assignments that are aligned to program learning outcomes to ensure that students are acquiring content knowledge that has been identified by program faculty and industry leaders as essential to the field of EPT. Program administrative faculty also conduct annual program reviews that are focused on critically examining student performance and areas of future program modification. Identified program modifications are focused on areas of program enhancement and the inclusion of current and future trends that potentially have significant impact on the field. Current program focuses include social justice, service learning, and innovative forms of technology that students may be exposed to in their future workplace settings. Students in the EPT program are provided the unique opportunity to experience these areas of learning through a global perspective in the online classroom.
Further, all program faculty are trained in Quality Matters (QM), which provides a solid foundation of accessible, equitable, and innovative components during the curriculum design of each program course. Additionally, TCSPP's online campus possesses the QM Online Learner Support Certification, which further illustrates the program's and institution's high level of commitment in providing quality and rigorous online educational experiences.

TCSPP also provides resources that promote student success. For example, the Online Campus Writing Center offers online students the opportunity to receive writing support and feedback on their course assignments, capstone projects, theses, and dissertations. Moreover, students have access to Methodology Experts to support them in their coursework and research projects. Students also are able to access resources and materials from the TCSPP online library and are able to engage in online chats and schedule consultations with TCSPP librarians.

The online EdD in EPT is a professional practice program that is designed to be completed in three years. Dissertation courses are integrated throughout the program to provide students the opportunity to complete their dissertation research while simultaneously enrolled in their coursework, thus providing students the opportunity to finish their degree in a timely manner and begin earning a higher salary upon completion of their studies. The program is also cost effective in that it was originally designed to ensure students are able to complete their doctoral studies while remaining in their full-time professional roles. For example, the program encourages students to identify problems of practice in their professional settings from which to conduct action research dissertations. This approach ensures that students are receiving doctoral experiences that are supportive and relevant to their careers and that they understand how they are able to effectively integrate the course content into their professional settings. Due to the vast array of professional opportunities that are available to current students and program alumni (e.g., instructional designers, consultants, trainers, curriculum specialists, administrators, university/college faculty members), students are provided significant access to a large number of career options through the completion of one doctoral degree of study.

Additionally, students have expressed their appreciation of having instructors who are practitioners with expertise in the content areas they are studying and for faculty motivating them to accomplish their goal of earning their doctorate degree. Examples of student testimonies include the following: "I appreciate how the instructors provide us examples of how we can use the topics we are learning in our professional settings," and "The faculty are really knowledgeable in the areas we are learning and they encourage me to continue moving forward in my coursework and research."

\section{ADVANCED TECHNOLOGY}

The EPT program faculty continually strive to add innovative design elements to online program coursework in order to prepare students for roles of leadership and advocacy in social change. Tools and platforms that have been used to enhance the EPT program include augmented reality, virtual reality, and gamification. Additionally, the EPT program faculty have developed specific plans to incorporate artificial intelligence (AI), drones, and robotics into coursework in the coming academic year. 
Students have also shared that their ability to explore innovative technologies has helped to enhance their levels of technology selfefficacy and their beliefs in their ability to implement similar trends in their own classroom and professional settings. As an example, one student stated that "the experiences and the knowledge I have acquired during the course of the EPT program thus far has been magnified during this task of game design. I enjoyed coming up with the gameplay and making the decisions of what the reward structure would be. Doing so, has really expanded my level of creativity as well as my learning and teaching expectations." Further, a student shared that "designing the US VR Tourism Game was a great experience. It really helped me to get over the misconception that creating technology should be reserved for those who work for major tech companies such as Google. I am more confident in my abilities to design curriculum and to integrate technology."

Additionally, the EPT program also launched a monthly podcast series, titled EdTech Hour, in which students are involved in researching, conducting, and editing interviews. This podcast series is vital in further expanding students' knowledge of course content and providing them important networking opportunities with professionals in the field. Through the podcast series, students are able to gain experience observing how global leaders in the field are able to utilize their educational training in order to positively influence others, discuss topics they are passionate about, and share their knowledge.

\section{SOCIAL JUSTICE AND TECHNOLOGY}

Doctoral programs have the potential to inform and educate students to become global agents of change by expanding students' knowledge about issues focused on inequities, disparities, and inhumanities. Thus, including specific course readings, class discussions, as well as assignments, provides students with practical experiences in planning and pursuing issues of social justice. As Marx and Kim (2019) posited,

in the past, much research on technology and equity in education focused specifically on access to technology for historically marginalized populations, such as children of color, children with disabilities, and children in poverty. The current ubiquity of technology, evidenced in our everyday use of mobile devices, computers, and social networking sites, has promoted broadening user demographics, alleviating some concerns about equitable access to technology as a tool. Recent research expands the discussion of equity and diversity in education by attending to the means by which technology is taught and used, how it can enhance user identity, and what inequalities remain. (p. 10.)

Further, and of important note when educating a diverse student body, the terms "social justice" and "equality" hold different meanings to different individuals and often are dependent on their personal backgrounds, religious beliefs, political views, and sociocultural and ethnic perspectives. For example, Smith (2012) explained that equity might mean "fairness in treating everyone equally (equality of opportunity), or might be treating people differently so that certain outcomes can become more equal, and therefore, more fair (equality of outcomes)" (p. xi)

For example, despite cultural and religious differences, Arar and Oplatka (2016), concluded in their study specifically evaluating measures of social justice in Arab and Jewish schools in the Middle East, that the four themes related to leadership in actions of social justice are: 1.) vision and values, 2.) the practical implementation of social justice, 3.) factors facilitating or obstructing the practice of a social justice school policy, and 4.) the socialization process of leaders for social justice.

Moreover, similar to what Arar and Oplatka (2016) expressed regarding their own research, doctoral programs should also strive to "contribute to the understanding of ways in which enlightened educators in a society dominated by inequitable practices can overcome political and cultural barriers and increase the potential for equity and social justice" (p. 71). Therefore, rather than specifically instructing students on what these terms mean and providing a concrete list of issues of social justice, it is critical that doctoral learners are encouraged to truly grapple with the definitions, issues, measures, and needed actions of social justice in order to most effectively prepare students to be knowledgeable and compassionate agents of change in their communities and worldwide. Rather than telling students what or how to think, students should be provided with skills that cultivate critical thinking as well as passion for helping others and an understanding of those different from themselves.

The EPT program has the unique opportunity to teach students about the potential for action through social justice with the use of technology, as a means to reach underserved populations as well as a means of protecting vulnerable populations. The EPT program includes three specific program learning outcomes related to social justice:

1. Demonstrate awareness and implications of biases, prejudices, and assumptions.

2. Explain how social justice issues are manifested in educational and organizational contexts.

3. Explain how social justice issues are manifested in educational and organizational contexts.

Through the EPT program's social justice initiatives, students are explicitly provided with practice training that offers opportunities for action through community engagement and social change with the use of technology. For example, in the EPT qualitative research course students are taught to develop a research proposal that focuses on a student's selected issue of social justice. Students are encouraged to think about ways to provide a voice for previously unheard or underserved groups through the use of qualitative research and technology. In the program course titled The Psychology of Motivation and Emotion in Learning, students explore the motivational factors and theories behind social justice actions and conduct a presentation on how technology can be used to enhance participation and engagement in social justice movements. Additionally, students analyze the potential for drone technology to assist in social justice movements, such as through the delivery of medical and food assistance in impoverished areas. Further, in the program's Proseminar in Education course, students write a persuasive essay focused on how educational technology can influence or impact social justice. Student are also asked if distance learning can used in the pursuit of social justice and what specific groups or persons might be most positively and negatively impacted by technology enhanced education. These assignments, as well as other course work in the program, are utilized to educate, prepare, and empower students to feel capable and confident in their abilities to be active agents of change in their roles in the fields of education and training. 


\section{SERVICE LEARNING AND STUDY ABROAD OPPORTUNITIES}

As Amerson (2019) recently shared, "ethical engagement, including the role of power and privilege, when working with vulnerable or indigenous populations also has moved to the forefront of the national dialogue" (p. 205). TCSPP holds this value of ethical engagement in social change in high regard and therefore has incorporated service learning projects throughout the university curriculum. Due to the online nature of the program, the EPT program recently adopted virtual service learning opportunities for students. For example, in the EPT Cognition Across the Lifespan and Technology's Impact online course, students created a servicelearning video intended to educate individuals in a specific stage of life, or caregivers to a specific stage, about learning, behaviors, emotions, or relationships through technology. In an effort to pursue social justice, students are instructed to view this service-learning project as an opportunity to advocate for special populations who are currently underserved or under-protected.

Amerson (2019) proclaimed the importance of appropriate student volunteer work in international service learning projects and explained the need for ethical work in host countries, primarily the need for students to engage in activities not "beyond their level of competence" (p. 205). Students in the EPT program have the opportunity to enroll in study abroad courses that focus on the implementation of course concepts into an international setting. Lundgren-Resenterra and Kahn (2019) posited that "professional doctorates have a clear impact on the personal and professional lives of the individual student who undertake them" (p. 407). The success of EPT study abroad programs supports this claim and have continually challenged students who participate in them to grow both personally and professionally.

One program that is offered annually for EPT students focuses on students developing an understanding of the South African educational, political, historical, and cultural landscapes. By participating in this study abroad program, students are afforded intensive service learning experiences in South African township primary schools. This study abroad program has been impactful for providing learners a better understanding of how the field of EPT is implemented in technology rich and technology sparse schools. Through this study abroad program, students receive hands-on, practical learning experiences of how to advocate for the equity in educational resources by creating professional development educator workshops and conducting program evaluation in an international context. Through these study abroad experiences, students are empowered to engage in social change in their own communities as well as internationally. Students who have completed the South Africa study abroad program have shared that they are "eternally grateful to have had this experience with a wonderful group of individuals" and that "the study abroad program was one of the most impactful experiences" that they have had and that it "has fundamentally changed" them. Study abroad programs are a vital component of the EPT program in providing students a foundational understanding of how to develop culturally and contextually appropriate training materials, the ability to engage in cross-cultural communications, and the opportunity to research and apply educational technology to impact teachers and students in globally diverse contexts.

\section{SCHOLARLY MENTORSHIP}

In their research, Zambo et al. (2015) explained that "doctoral students must make sacrifices [therefore,] it is important that they value learning, understand their learning habits, and carve out time for learning [in] their busy lives" (p. 248). Moreover, they proclaimed that these steps and prioritizing time towards the doctorate ultimately brings pride and success for the student. In order to bridge the gap between a student's goals and the steps it takes reach their goals, as described by Zambo et al. (2015), the TCSPP EdD program relies heavily on faculty mentorship and student and faculty relationships.

As Godskesen and Kobayashi (2015) explained, "doctoral students need supportive learning structures as well as encouragement and space to develop agentive competences in the academic environment" (p. 146). In this regard, EPT administration and faculty provide support to students through one-on-one mentoring relationships; semesterly student outreach; and studentled, faculty supported research groups. Through these facultystudent relationships, EPT students have successfully collaborated with their peers as well as with faculty members in order to conduct research studies and produce effective scholarship, namely presentations and written work.

In the student-led research groups, students select research socially conscious topics related to their interests, which are often focused on issues of social justice, and are guided through virtual monthly research meetings held with the supervising faculty members. During these cooperative sessions, faculty provide students with suggestions, recommendations, potential submission options, and ethical guidance in support of their research goals. Students participating in these groups have completed studies on K12 learning, university learning, professional development communities, university assessment procedures, and diversity. Faculty supported research groups are beneficial in not only developing the research abilities and scholarly writing skills of students, but also in supporting students to continue to grow into their roles as agents of change in their professional roles.

In terms of the dissertation, EPT faculty provide ongoing and supportive access for their dissertation students. Brodin (2018) supported the necessity for dissertation supervisors to not act as gatekeepers, but as a "valuable intellectual resources" (p. 671). The dissertation chairs in the EPT program embrace this notion closely by encouraging students to select research topics they are passionate about and also that benefit their personal and/or professional communities and impact social change. Further, Godskesen and Kobayashi (2015) noted the value of coaching relationships with doctoral students. In this regard, EPT dissertation chairs communicate closely and regularly with students by holding virtual dissertation open houses and virtual and in-person meetings. Further, chairs hold round table discussions at program residencies to provide different scholarly perspectives of potential research studies students may have interest in pursuing. Through these mentoring and coaching relationships, students experience the benefits of advocacy as learners and in turn feel empowered to advocate on behalf of others through their roles in education and other social justice initiatives. 


\section{CONCLUSION AND DISCUSSION OF THE FUTURE OF DOCTORAL PROGRAMS}

As Zambo et al. (2015) posited, "the educational doctorate $(E d D)$ is being re-envisioned as a distinct professional degree. Today's EdD graduates are envisioned as scholarly practitioners" ( $p$. 233). Further, their research indicated that many students apply to EdD programs to be challenged and that EdD students value a sense of growth and empowerment from their doctoral programs. In contrast, Brodin (2018) postulated that doctoral education students may experience a "stifling silence" in their scholarly creativity due to "controlling intellectual, political, and economic agendas that enabled stifling conditions of the students' scholarly creativity" (p. 655). EdD programs must be cognizant of the potential for specific agendas to suppress student creativity in their research. Instead, programs should strive to grow and evolve as scholarly doctoral institutes of learning, as individuals invested in the success of students, as providers of educational training, and as supporters of developing agents of change who can advocate on behalf of underserved and underrepresented communities. TCSPP's EdD program is dedicated to inspiring student action through the development of agents of change. Students are provided with the unique opportunity to explore movements of social justice, equity, and service learning through innovative technology platforms and tools. Through curriculum rigor, providing students access to advanced and cutting edge technologies that are transforming the landscape of educational and organizational learning, as well as individual and personalized mentorship, students are challenged to make their learning practical in order to empower students to make an impact through action and advocacy in their global and local communities.

\section{REFERENCES}

Arar, K. H. \& Oplatka, I. (2016). Making sense of social justice in education: Jewish and Arab leaders' perspectives in Israel. Management in Education, 30(2), 66-73. https://doi.org/10.1177/0892020616631409

Amerson, R. (2019). Transforming Global Service Learning Experience. Journal of Transcultural Nursing, 30(2), 205. https://doi.org/10.1177/1043659618812946

Brodin, E. (2018). The stifling silence around scholarly creativity in doctoral education: Experiences of students and supervisors in four disciplines. Higher Education, 75(4), 655-673. https://doi.org/10.1007/s10734-017 0168-3

Ciok, J. (2019). What does it mean to be an agent of change? https://www.educationpioneers.org/blog/what-does-it-mean-be-agentchange

Godskesen, M. \& Kobayashi, S. (2015). Coaching doctoral students-a means to enhance progress and support self-organisation in doctoral education. Studies in Continuing Education, 38(2), 145-161. https://doi.org/10.1080/0158037X.2015.1055464

Kremers, K., Liepins, A., \& York. A. (2019). Developing change agents: Innovative practices for sustainability leadership. M Libraries Publishing. https://dx.doi.org/10.24926/97819461

Lundgren-Resenterra \& Kahn (2019). The organisational impact of undertaking a professional doctorate: Forming critical leaders. British Educational Research Journal, 45(2), 407-424. https://doi.org/10.1002/berj.3503

Marx, S. \& Kim, Y. (2019). Technology for equity and social justice in education: Introduction to the special issue. International Journal of Multicultural Education, 21(1), 1. http://dx.doi.org/10.18251/ijme.v21i1.1939
Smith, E. (2012). Key issues in education and social justice. SAGE.

Zambo, D., Buss, R., \& Zambo, R. (2015). Uncovering the identities of students and graduates in a CPED-influenced EdD program. Studies in Higher Education, 40(2), 233-252. https://doi.org/10.1080/03075079.2013.823932 